In press, Pure and Applied Geophysics, January 2020

\title{
Asperity failure control of stick-slip along brittle faults
}

\author{
Xiaofeng Chen ${ }^{1,2}$, Brett M. Carpenter ${ }^{1}$, and Ze'ev Reches ${ }^{1}$ \\ ${ }^{1}$ School of Geosciences, University of Oklahoma, Norman OK 73019 \\ ${ }^{2}$ Current address: Department of Geology \& Geophysics, Texas A\&M University, College \\ Station TX 77843
}

\section{Highlights:}

- Stick-slips are spontaneous, unstable events viewed as earthquake analogues

- The lock-and-fail of asperities is a likely mechanism of stick-slip sliding on brittle faults Surface mapping of experimental faults reveals many asperities susceptible to failure - Inherent strength and fault geometry control events' stress-drop and slip-distance

\begin{abstract}
Stick-slips are spontaneous, unstable slip events during which a natural or man-made system transitions from a strong, sticking stage to a weaker, slipping stage. Stick-slips were proposed by Brace and Byerlee (1966) as the experimental analogue of natural earthquakes. We analyze here the mechanics of stick-slips along brittle faults by conducting laboratory experiments and by modeling the instability mechanics. We performed tens of shear tests along experimental faults made of granite and gabbro that were subjected to normal stresses up to $14.3 \mathrm{MPa}$ and loading velocities of $0.26-617 \mu \mathrm{m} / \mathrm{s}$. We observed hundreds of spontaneous stick-slips that displayed shear stress drops up to $0.66 \mathrm{MPa}$ and slip-velocities up to $14.1 \mathrm{~mm} / \mathrm{s}$. The pre-shear and postshear fault surface topography were mapped with atomic force microscopy at pixel sizes as low as $0.003 \mu \mathrm{m}^{2}$. We attribute the sticking phase to the locking of touching asperities and the slipping phase to the brittle failure of these asperities, and found that the fault asperities are as strong as the inherent strength of the host rock. Based on the experimental observations and analysis, we derived a mechanical model that predicts the relationships between the measured stick-slip properties (stress-drop, duration, and slip-distance) and asperity strength.
\end{abstract}




\section{INTRODUCTION}

Stick-slips are spontaneous, unstable slip events that have been observed in a very wide range of natural and experimental shear systems. To mention a few, stick-slips were documented in nanoscale slip along crystalline surfaces (Rastei et al., 2013), granular flow (Ahronov and Sparks, 2002), direct shear of rock blocks (Leeman et al, 2018), and high-pressure rock-mechanics experiments (Brace and Byerlee, 1966). It is generally agreed that these events reflect intense and abrupt weakening during which a physical system transitions from a strong, sticking stage to a weaker, slipping stage; yet, the controlling mechanisms are not universal. Stick-slips have been widely observed in laboratory experiments of shear along experimental faults (e.g. Engelder and Scholz, 1976; Leeman et al., 2018). Brace and Byerlee (1966) indicated the similarity between the instability of experimental stick-slips and natural earthquakes, and postulated that they are the laboratory analogues of natural earthquakes. However, Brace and Byerlee (1966) did not analyze the mechanical processes that control the stick-slips, and later Scholz (1992) stated " $[\ldots]$ the crowning achievement [...] of W.F. Brace was the announcement, in Brace and Byerlee (1966), of the stick-slip theory of earthquakes. This constituted a new paradigm for a major earth process, with a potential influence that extended far beyond the confines of Brace's field of rock mechanics $[\ldots]$ this paradigm has not yet, 25 years later, been consensually accepted into the world view of seismologists [...]. If the measure of completion of a scientific revolution is the near-universal acceptance of a new paradigm, then this one is certainly not over." The observed weakening was widely explained in terms of the static/dynamic friction formulation (Dieterich, 1978; Scholz, 1998), but friction formulation does not reveal the physical processes controlling the weakening. We focus here on the mechanical processes associated with stick-slips along brittle experimental faults.

Typically, stick-slips along experimental faults are short-lived events with durations of microseconds to milliseconds, displacements up to a few tens of microns, and slip velocities of a few $\mathrm{cm} / \mathrm{s}$ to $\sim 1 \mathrm{~m} / \mathrm{s}$ (e.g., Ohnaka et al., 1987). Stick-slip events are typically associated with intense, rapid weakening during which the shear-stress may drop by 10-90\% (Brace and Byerlee, 1966; Jaeger and Cook, 1969; Karner and Marone, 2000; Passelègue et al., 2016). Fault weakening of such intensity may develop by local asperity melting during displacements of a few tens of microns in high normal-stress experiments (e.g., Fig. 9 in Passelègue et al., 2016). 
However, comparable intense weakening requires long displacements of 0.5 - $2 \mathrm{~m}$, or even more, in low-normal-stress experiments, (e.g., Niemeijer et al., 2011; Di Toro et al., 2011; Reches and Lockner, 2010; Chen et al., 2017). We focus here on stick-slip events that occur during short displacements under low-normal stress, and analyze asperity failure as the controlling weakening mechanism of these events.

Byerlee (1970) recognized the above difficulties and proposed that "an instability caused by sudden brittle fracture of locked regions on surfaces in contact is the most likely explanation for stick-slip during dry frictional sliding of brittle rocks at room temperature." This conclusion was partly based on the experimental work of Byerlee (1967) which indicated that faults with highly smooth surfaces have friction coefficients $\mu \sim 0.1$, whereas faults with interlocking asperities displayed $\mu \sim 1$.3. Many experiments have demonstrated that slip along bare surfaces of brittle rocks is dominated by the failure of isolated asperities (Fig. 1) (Scholz and Engelder, 1976; Boneh et al., 2014; Tesei et al., 2017; Yamashita et al., 2018; Boneh and Reches, 2018). Further, the concept of asperity failure was adopted as a mechanism of unstable slip and radiation in experimental observations (McLaskey and Glaser. 2011), and seismic radiation of natural earthquakes (Das and Kostrov, 1986). We follow the hypothesis of Byerlee (1970) and analyze the mechanics of stick-slips as events governed by brittle asperity failure. We test the model derivations by shear experiments with granite and gabbro faults and nanoscale observations.
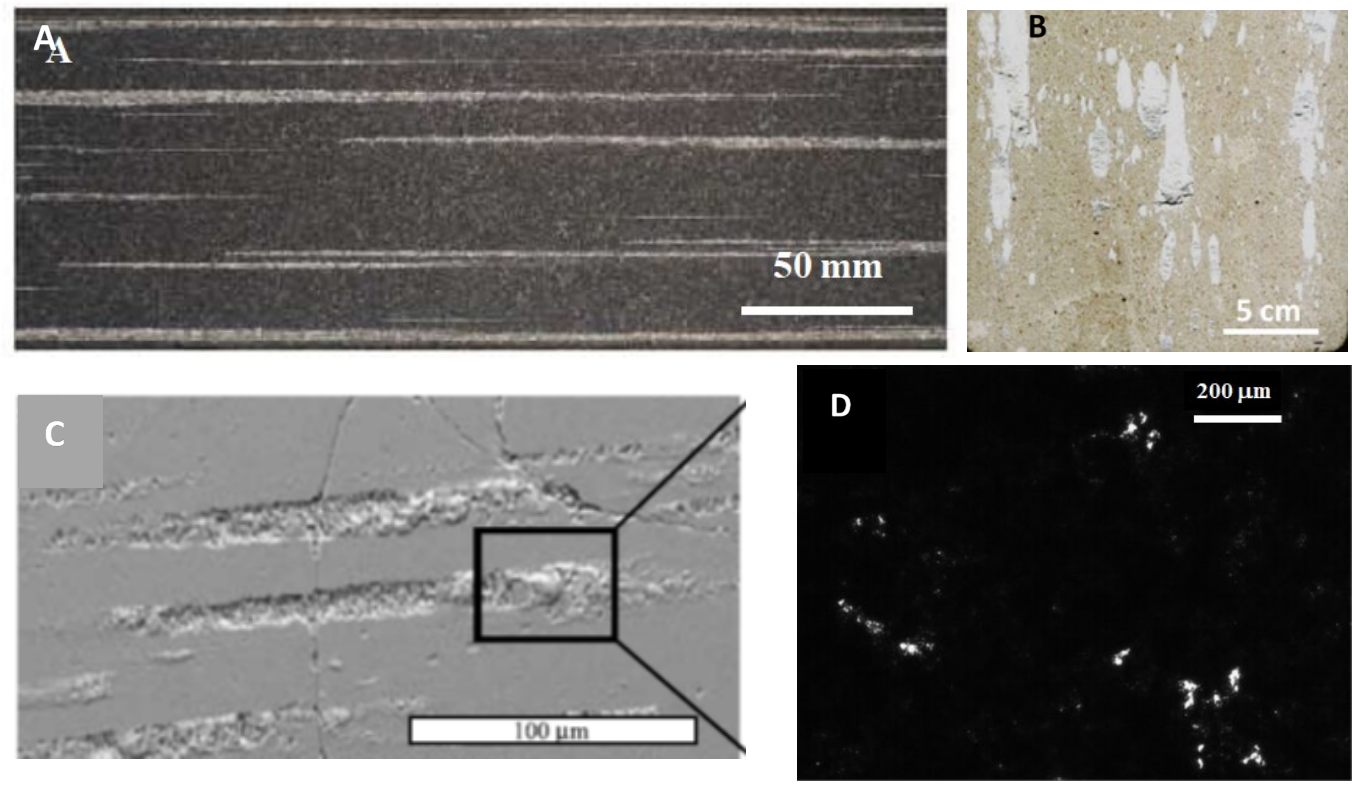
Figure 1. Close-up of experimental fault slip surfaces displaying fragmented asperities and surface damage under shear at the noted normal stress $(A-C)$ and prior to shear (D). A. Metagabbro, $\sigma_{n}=6.7 \mathrm{MPa}$ (Yamashita et al., 2018); B. Limestone, $\sigma_{n}=5 \mathrm{MPa}$ (Tesei et al., 2017); C. Granite $\sigma_{n}=20 \mathrm{MPa}$ (Koizumi et al., 2004); D. Asperity contacts of a quartz block $\sigma_{n}$ $=30 \mathrm{MPa}$ before shear (Dieterich and Kilgore, 1996).

\section{MiCROMECHANICS OF STICK-SLIPS}

\subsection{HYPOTHESIS}

We consider a fault that is composed of two brittle blocks with planar, rough surfaces (Fig. 2). The fault is under normal stress and is loaded by a constant, remote velocity parallel to the surfaces. The blocks contact each other at touching asperities (Fig. 2A), and the real contact area, $A_{a}$, is a small fraction of the nominal fault area, $A_{o}$, i.e., $r=A_{a} / A_{o}<<1$. The local stresses at the touching asperities are amplified relative to the macroscopic, nominal applied stress, and the local stress can be as high as the material strength (Tabor, 1975, 2006). On a planar fault with a small r, the touching asperities are isolated (Fig. 1D) (Dieterich and Kilgore, 1996), and are not likely to interact with each other.

The considered evolution of a stick-slip event is schematically shown in Figs. 2B-2D. First, the normal stress is supported by a pair of asperities at site \#1 that locks the fault. Then, upon remote velocity loading, the shear stress increases locally, deforms the locked asperities, and the upper asperity at site \#1 starts climbing over the lower asperity which increases the local normal stress, shear stress, and dilation (small, black arrows at site \#1, Fig. 2B). Eventually, the local stresses exceed the asperities' strength, the asperities fail, and the upper block slips with no resistance between the isolated asperities (Fig. 2C). The slip induces simultaneous drop of the normal and shear stresses, and compaction relative to the locked stage. The slip continues until a new pair of asperities come into contact at site \#2 (Fig. 2D). If the local stresses at site \#2 are below the asperities' strength, the fault enters a new sticking stage (Fig. 2D) of a new stick-slip cycle.

This idealized model of the stick-slip process is described for two pairs of asperities. However, in a physical rock experiment, the locking-and-failure stages occurs at assemblages of touching asperities that lock and fail quasi-simultaneously. Finally, the present model considers 
isolated asperities on a planar, rough fault, without reference to the friction coefficient or the presence of a gouge or a granular layer between the two blocks. The effects of such layers are discussed later.
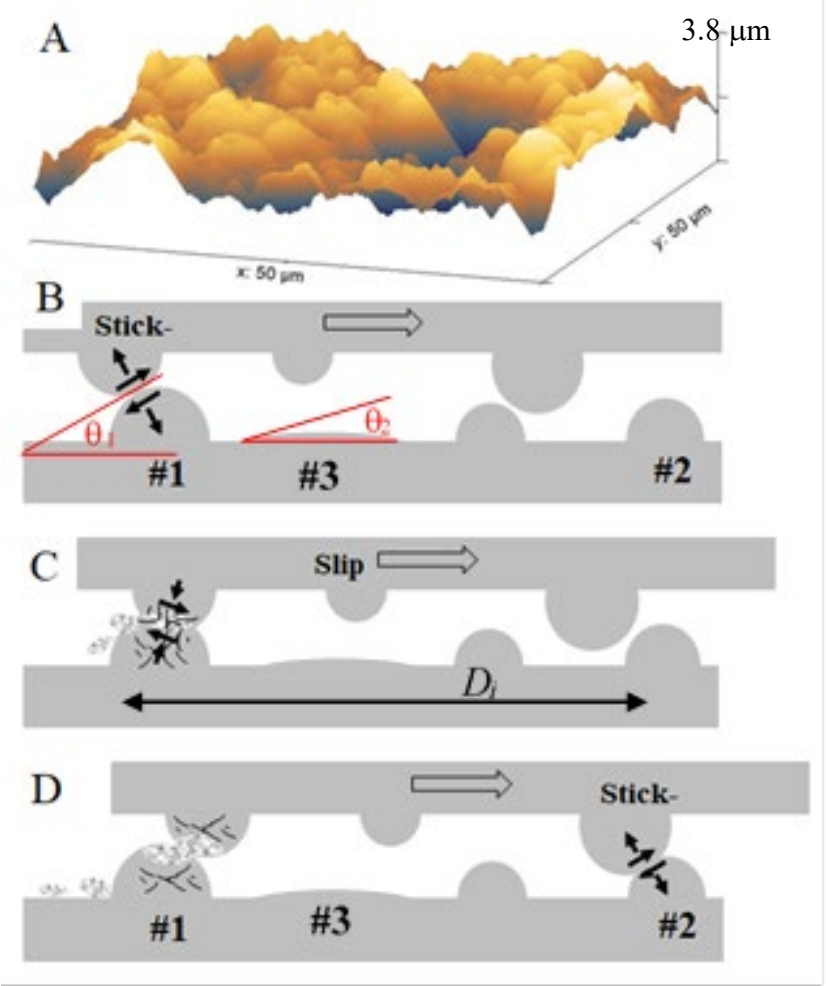

Figure 2. Stick-slip model configuration. A. Surface topography of a planar, rough surface of a granite block; ground flat and roughened with \#600 powder; mapped by AFM (note scales). B-D. Display of the three stages of an idealized stick-slip event (see text).

\subsection{STRENGTH AND FAILURE OF FAULT ASPERITIES}

We investigate the mechanics of stick-slips along experimental faults in terms of the above hypothesis: the stick stage is controlled by locked asperity pairs (\#1 in Fig. 2), and the slip stage indicates their failure and re-locking by another pair (\#2 in Fig. 2). The characteristics of the $\mathrm{i}^{\text {th }}$ stick-slip event are determined by two parameters: (1) The yielding strength, $U_{i}$, of the locking asperities, and (2) the slip-distance, $D_{i}$, between the yielding asperities and the next, re-locking asperities (arrow in Fig. 2C). Thus, $U_{i}$ controls the peak shear-stress, $\tau_{\mathrm{p}}$, of the fault before slip initiation, and $D_{i}$ controls the slip distance during the event. For shear experiments at room 
conditions, the yielding strength, $U_{i}$, depends on several properties: $S$, the strength of the fault rocks (the strength will be defined later); $R$, the shape of the asperities; $\sigma_{n}$, the applied normal stress; and the time for asperity healing and/or creeping during the sticking period. The sticking period depends on the applied remote velocity, $V$ (e.g. Karner and Marone, 2000). Thus, the locking asperity strength is

$$
U_{i}=f\left(S, R, \sigma_{n}, V\right) .
$$

The interrelationships of these properties are evaluated below by using the experimental observations. Finally, during the slip stage, part of the accumulated elastic energy is released, and the stress-drop of the $i^{\text {th }}$ event is

$$
\Delta \tau_{i}=K \cdot D_{i}
$$

where $K$, and $D_{\mathrm{i}}$ are the elastic stiffness of the loading system and the slip-distance during the event, respectively.

\subsection{ASPERITY LOAD}

As shown in equation (1) above, the asperity strength, $U_{i}$, is a manifestation of a few mechanical properties, and to resolve their relationships we follow the analyses of Greenwood and Williamson (1966), Whitehouse and Archard (1970), and Tabor (1975). They explored the

mechanics of pressing a metal block with rough surface against a flat metal block, a configuration similar to the present idealized model in Fig. 2. The application of normal stress, $\sigma_{n}$, in this setting increases the asperities contact area by the combination of elastic deformation, asperity failure, and bringing additional asperities into contact (Dieterich and Kilgore, 1996; Tabor, 2006). Due to these processes, the normal stress at the touching asperities, $\sigma_{A}$, can be roughly considered independent of the nominal, applied normal stress, $\sigma_{n}$ (Greenwood and Williamson, 1966). Tabor (1975) derived a simple, general expression for the asperity normal stress, $\sigma_{A}$,

$$
\sigma_{A} \approx E \tan \theta
$$

where $\theta$ is the local slope of the asperities (shown schematically in Fig. 2B) and $E$ is the Young's modulus of the blocks (Tabor, 1975, equation 5).

Next, these analyses (Greenwood and Williamson, 1966; Whitehouse and Archard, 1970), assumed that plastic deformation initiates at the asperities when the stress exceeds the hardness, 
$H$, of the metal. Hardness integrates multiple failure properties including plasticity, and brittleness (Boneh and Reches, 2018), and it is measured at small scales, which are relevant to the asperities' size. The derivations of Tabor (1975) demonstrate that the transition from elastic deformation to plastic deformation occurs at asperities with local slopes which exceed the critical angle $\theta_{\mathrm{C}}$ of

$$
\tan \theta_{C}=(0.6 \sim 1.0) \frac{H}{E}
$$

Tabor (2006, Table 7.1) applied equation (4) to several industrial materials and found that the critical slope angle ranges from $\theta_{C} \sim 0.5^{\circ}$ for annealed metals to $\theta_{C}>20^{\circ}$ for cross-linked plastics (Table 1). Equation 4 implies that in our model, an asperity with large $\theta_{1}>\theta_{C}$ (\#1 in Fig. 2B) is susceptible to failure, whereas an asperity with small $\theta_{2}<\theta_{C}$ ( $\# 3$ in Fig. 2B) will deform only elastically.

\subsection{AN EXPERIMENTAL INVESTIGATION OF THE MODEL}

In the above sections (2.1-2.3), we presented a model of stick-slip mechanics based on asperity failure (Fig. 2). In the following sections, we test this model by describing the observed stick-slips in our experiments with granite and gabbro faults, and then investigating the observations considering the above model. We follow these steps:

A. We use atomic force microscopy (AFM) to map the surface topography of planar, rough experimental faults (Appendix). The AFM data is used to determine the local slopes of the mapped surfaces, and the fraction of the surface slopes at angle $\theta$.

B. Asperities with local slope equal or exceeding the critical slope, $\theta \geq \theta_{C}$, (equation 4) are susceptible to fail, and we use the fraction of failure susceptible asperities to evaluate the asperities strength, $U_{i}$ (equation 1). It is again noted that non-touching asperities (too low), and asperities with $\theta<\theta_{C}$ are not expected to fail.

C. In our model (Figs. 2B-2D) the slip-displacement during a stick-slip event is controlled by the distance between touching asperities that are capable of locking and failing. We measure the distances between the peaks of high asperities on the AFM images, and we expect that the high asperities on one block will be the first to touch the high asperities in the opposite block. Thus, it is assumed that the measured asperity distances are comparable to the slipdisplacements during the experimental stick-slips. 
D. The present analysis focuses on stick-slip mechanics in terms of brittle failure of fault asperities, and the analysis centers on strength parameters $\left(\mathrm{U}_{\mathrm{i}}, \mathrm{S}\right.$, and $\mathrm{H}$ in the equations above) and fault geometry parameters ( $R, D_{i}$, and $\theta$ in the equations above). No attempt is made to investigate the effects of normal stress and applied velocity (equation 1).

E. The present experimental setting, similar to common rock friction apparatuses, does not allow for the analysis of a single asperity on a flat surface or two touching asperities. Thus, we examine the asperities on AFM images of one fault block, and assume that the opposite block has similar asperity distribution.

\section{EXPERIMENTAL OBSERVATIONS}

\subsection{EXPERIMENTAL SETTING AND PROCEDURE}

We conducted shear experiments on a rotary shear apparatus that is described in the Appendix and by Reches and Lockner (2010). The experimental faults were composed of Sierra White granite (SWG) and Raven Noir gabbro (RNG). The samples are cylindrical with a raised ring (Fig. A1A), and the bare fault surfaces were ground flat, followed by roughening with \#600 powder (Appendix). The ring geometry provides a closed loop fault with a continuous boundary condition (i.e., without an 'end') that is equivalent to an infinitely long fault. During the experiments, the fault was loaded to a constant normal stress ranging from 10.2 to 14.3 $\mathrm{MPa}$ and subjected to constant remotely applied velocities ranging from 0.26 to $617 \mu \mathrm{m} / \mathrm{s}$. All experiments were conducted at room conditions of temperature and humidity. The monitoring system continuously recorded the shear stress, normal stress, and displacement along the fault, as well as recording of the acoustic emission during part of the experiments (Table A1). Note that both shear stress and fault displacement are measured at the base of the blocks that were $\sim 10 \mathrm{~cm}$ away from the fault surface (Appendix). Thus, the measured displacement and velocity values were corrected to reflect slip along the fault surface (section 4.3). A typical experiment includes an early stage of quasi-linear increase of the shear stress while the fault is locked followed by a stage of multiple stick-slip events (Figs. 3A, B) similarly to previous experimental observations (e.g., Karner and Marone, 2000). 


\subsection{OBSERVATIONS}

\subsubsection{Periodic stick-slips}

We analyzed 209 stick-slips in 15 runs on the RNG fault under normal stresses of 11.7-14.2 MPa and applied velocities of 0.26-9.54 $\mu \mathrm{m} / \mathrm{s}$ (Table A1). The stick-slips display repeatable, systematic periodicity (Fig. 3A) that is controlled by the applied normal stress and remote slipvelocity. The events display stress-drops of 0.05 to $0.6 \mathrm{MPa}$, event displacements of 3.25 to $17.58 \mu \mathrm{m}$, rise-times of 101 to $780 \mathrm{~ms}$, and peak slip-velocities of 28 to $257 \mu \mathrm{m} / \mathrm{s}$ (Table A1). For the RNG sample in our loading system, the measured shear stiffness and normal stiffness are $0.184 \mathrm{MPa} / \mu \mathrm{m}$ and $0.171 \mathrm{MPa} / \mu \mathrm{m}$, respectively.

\subsubsection{Non-periodic stick-slips}

We analyzed 281 stick-slips in 22 runs on the SWG fault under normal stresses of 10.5-14.3 MPa and applied velocities of 16-617 $\mu \mathrm{m} / \mathrm{s}$ (Table A1). The SWG stick-slips were non-periodic and irregular in timing, and typically are preceded by a creeping stage (Fig. 3B). These stick-slips have stress-drops ranging from 0.009 to $0.663 \mathrm{MPa}$, event displacements ranging from 0.09 to $11.92 \mu \mathrm{m}$ with no clear dependence on normal stress or loading rate over the tested ranges. The duration of these irregular stick-slips ranges from 0.4 to $1.6 \mathrm{~ms}$, resulting in high peak velocities ranging from 188 to $14,159 \mu \mathrm{m} / \mathrm{s}$ (Table A1). Stick-slips along the SWG fault were observed only at normal stresses higher than 10.5 MPa. The measured shear stiffness of the SWG sample in our loading system is $0.089 \mathrm{MPa} / \mu \mathrm{m}$, and the measured normal stiffness is $0.092 \mathrm{MPa} / \mu \mathrm{m}$. The stick-slips along the SWG fault display three distinct stages. First, after a slip event, the shear stress increases linearly, and the fault is loaded elastically (Zone "Elastic" in Fig. 3D). Then, the fault reaches the yielding point (Yield in Fig. 3D), and switches to non-linear creep to peak stress (Peak in Fig. 3D). The fault is no longer locked during the creep stage, and it may accommodate long slip-distance during this stage. Finally, the fault reaches another major slip stage with an abruptly high-velocity slip over a short duration, associated with shear and normal stress drops and acoustic emission (Fig. 3C). The events along the RNG fault (Figs. 3A,C) displayed similar stages, yet the elastic loading stage was significantly longer that the creeping stage. The following analysis focuses in the SWG events and their relationship to the proposed model. 

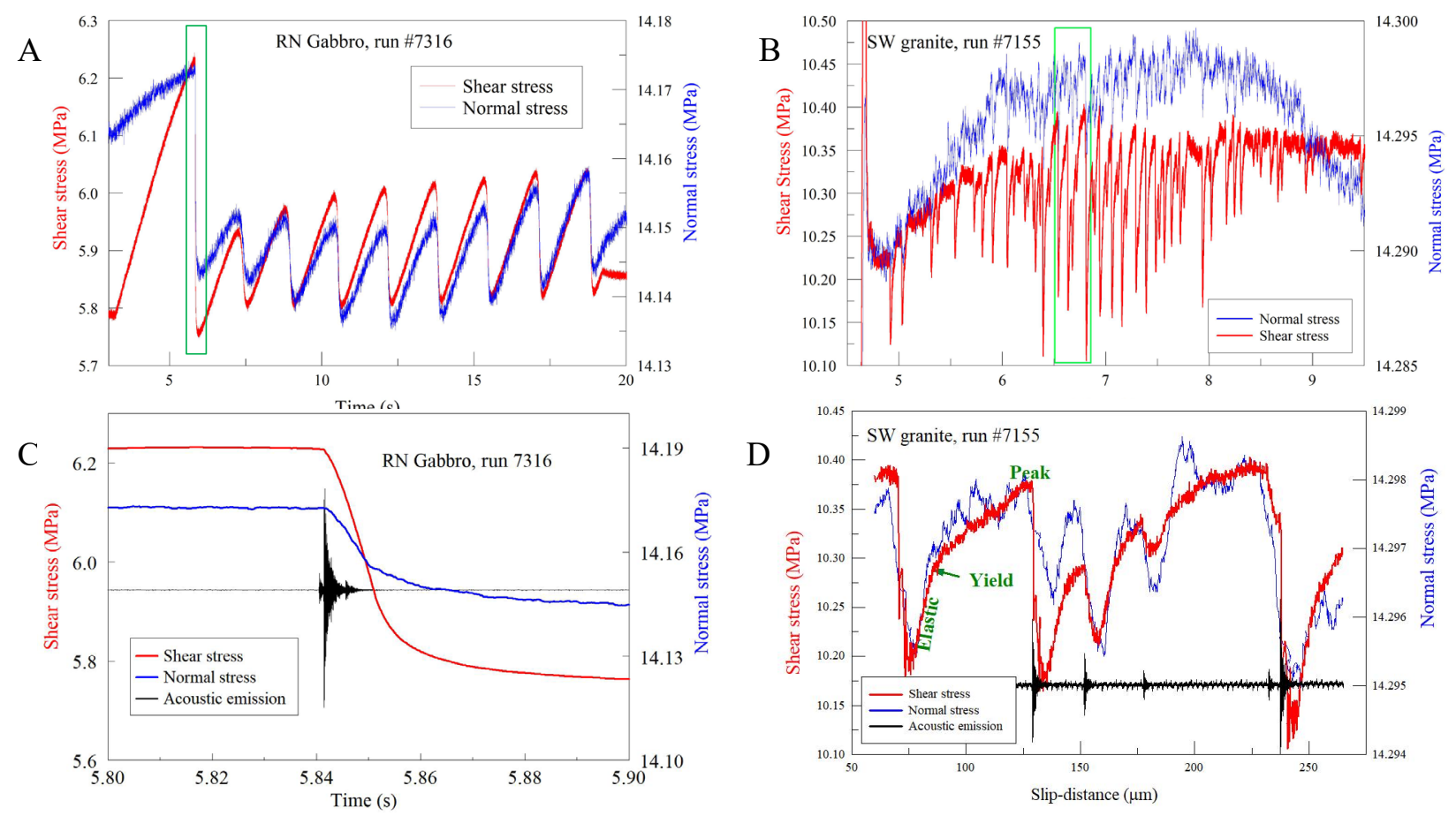

Figure 3. Experimental observation of stick-slips; note the synchronous rise and drop of the shear and normal stresses in the three plots with separate scales for the two stress components. A. Periodic events along a gabbro fault (run 7316 with applied remote velocity of $3.87 \mu \mathrm{m} / \mathrm{s}$ (Table A1). B. Non-periodic events along a granite fault (run 3155) with remote velocity of 617 $\mu \mathrm{m} / \mathrm{s}$. C. Details of the green rectangle in 3A; acoustic emission acceleration shown at arbitrary scale. D. Details of the green rectangle in 3B; 'Elastic', 'Yield' and 'Peak' mark phases of the stick stage; acoustic emission acceleration shown at arbitrary scale (see text).

\section{Model investigation}

In the present experiments, we identified and analyzed 490 stick-slip events in 37 shear runs along granite and gabbro faults (above). We now use these data to test the proposed model. The model predicts the relationships between fault geometry and asperity strength $U_{i}$ (equations 1,4 ) and the relationships between stress-drop and asperity distribution and loading stiffness (equation 2).

\subsection{FAULT ROUGHNESS CONTROL OF ASPERITY BRITTLE FAILURE}

The brittle failure of isolated asperities during fault slip has been experimentally observed (Fig. 1), but the geometrical control of this failure has not been quantified for rock faults. Based 
on the analyses of plastic deformation of metal surfaces (Greenwood and Williamson, 1966; Tabor, 1975, 2006), we proposed above that equation (4) can serve as the critical condition for brittle failure of asperities on a planar, rough rock surface. The relevant properties for this condition are Young's modulus $(E)$, hardness $(H)$, and local surface slope $(\theta)$. The first two properties are available from published rock-mechanics analyses (Table 1). Boneh and Reches (2018) showed that micro-hardness is an effective variable to quantify the failure of brittle asperities on experimental faults composed of granitic, carbonate, and sandstone blocks (their Fig. 5). Table 1 indicates that for the measured ranges of $E$ and $H$, the critical asperity slope for brittle failure is in the range of $6^{\circ}-17^{\circ}$ for granite and gabbro. Namely, asperities with slopes below these critical angles will deform elastically, whereas asperities with larger slopes will fail in a brittle style.

To quantify the asperities slopes, we used an AFM to map roughened surfaces of the experimental faults (Appendix). AFM maps cover regions of tens of microns (Chen et al., 2013), which is the relevant scale of slip-displacements for the experimental stick-slips (Table A1). We mapped 6 polished pre-shear surfaces and 13 post-shear surfaces from SWG, and 4 post-shear surfaces from gabbro. Our AFM device requires small samples, and the strong gabbro samples did not fracture prior to shear; thus, we mapped 4 pre-shear surfaces of a fractured diorite sample as a proxy for the gabbro. Figs. 4A-D display typical AFM surface maps that show only the areas above the mean height, with areas below the mean height blacked out. This cutoff is based on the assumption that only asperities above the mean height would interact with the other block. The distributions of the local slopes (Fig. 4E, F) were determined for the areas above the average height in 26 AFM sites (Appendix). The determined distributions reveal a few distinct features (Table 2):

(1) For pre-shear surfaces, the local slopes range from $0^{\circ}$ to $75^{\circ}$. The frequency distribution of the slopes indicates that $90 \% \pm 4 \%$ are steeper than $6^{\circ}$, and that $54 \% \pm 16 \%$ are steeper than $17^{\circ}$. Namely, most of the asperities above the mean height are expected to fail according to equation 4 (compare with Table 1);

(2) Sheared surfaces have a smaller portion of steep slopes than pre-shear surfaces, indicating the elimination of asperities by wear of the steeper parts during shear (Figs. 4E, F). 
These geometric features and the implied failure susceptibility agree with the model conditions, and strongly support the validity of the central assumption that asperity failure controls the stick-slips. While we focus here on unstable stick-slips, many quasi-static shear analyses documented the failure of isolated asperities or sets of asperities (Fig. 1) (Scholz and Engelder, 1976; Boneh et al., 2014; Tesei et al., 2017; Yamashita et al., 2018). We envision that the mechanical control of the asperity failure in those cases is also the local surface slope as analyzed and documented here.
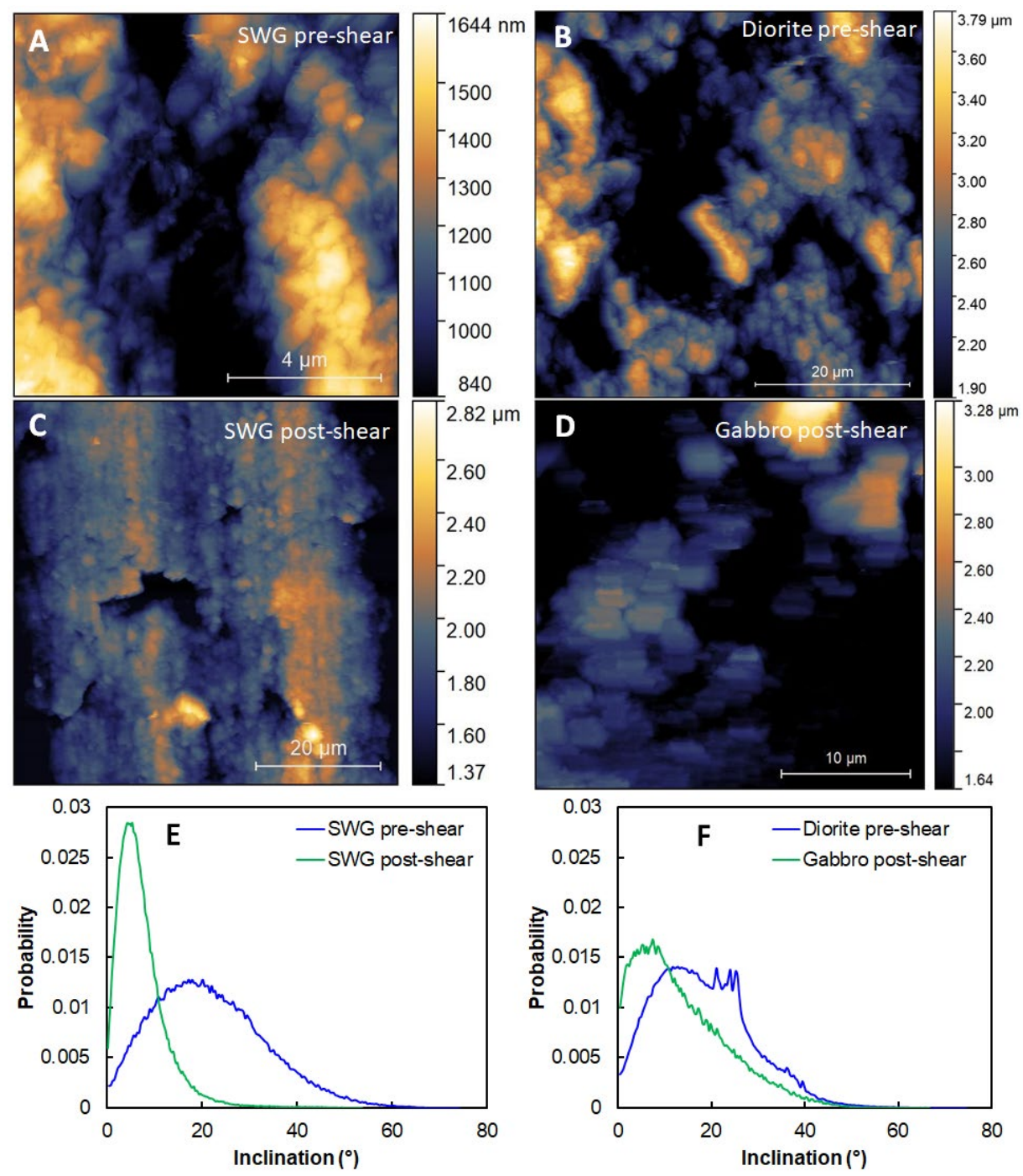

Figure 4. Typical AFM topographic images of pre-shear and post-shear slip surfaces for granite, gabbro, and diorite samples $(A-D)$ and their associated inclination probability distribution (E, F). A diorite pre-shear is used as a proxy to the pre-shear gabbro (see text). 


\subsection{ASPERITY STRENGTH}

In this section, we evaluate the asperity strength $U_{i}$ as appears in equation 1 , and we employ a few strength terms. The 'yield-strength' and 'ultimate-strength' parameters (Fig. 5A, B) are commonly used in rock mechanics analysis (Lockner, 1995). The 'hardness' parameter (Table 1) was previously used to evaluate asperities' strength (Tabor, 1975; Dieterich and Kilgore, 1996; Boneh and Reches, 2018). 'Inherent strength' is also used in the analysis of internal friction. For example, Savage et al. (1996) found that faulting of intact granite samples is dominated by microcracks and bridges of intact rock between the micro-cracks. In their model, macroscopic failure occurred by frictional slip along the microcracks and shear failure of the intact bridges. Savage et al. (1996) showed through shear experiments that the strength of the intact bridges is the inherent strength, $S_{I}$, of the granite, and evaluated $S_{I} \sim 1,000 \mathrm{MPa}$. They further realized that this value is in the right order of the ultimate strength of a perfect material after Hirth and Lothe (1968). We now show that the inherent strength is an effective parameter to evaluate the asperity strength, namely that $U i \sim S_{I}$.

We first examine the structure and distribution of the asperities. The analyses of fault surface geometry reveal self-affine roughness from sub-micron scale in experiments (Chen et al., 2013), to tens of meters of active natural faults (e.g., Power et al., 1988; Sagy et al., 2007). Three characteristic features of these rough surfaces are relevant here. First, the elevated asperities (Fig. 4) are likely to contact and lock against the elevated asperities on the other fault block. The AFM maps show that $\sim 54 \%$ of the upper-half of the pre-shear granite surfaces, and $\sim 25 \%$ of the upperhalf of the post-shear surfaces are susceptible to failure, (Fig. 4, Table 2). Second, the elevated asperities are isolated as observed in the fault surface maps (Figs. 4A, B, A2), and views of smeared asperities on fault surfaces (Fig. 1A-C). Third, experimental observations confirmed that the touching asperities are separated by large regions of no contact under normal load (Fig. 1D). Due to their separation, the isolated asperities lock-and-fail independently, and as discussed above, the failure is facilitated by the local stress amplification and local slope (Table 2; Fig. 4) (Greenwood and Williamson, 1966; Whitehouse and Archard, 1970; Tabor, 1975; Byerlee, 1970, Dieterich and Kilgore, 1996). This occurrence of isolated, elevated asperities that are susceptible to failure is the central component of the present model (Fig. 2), and this failure is manifested in the macroscopic experimental stick-slips (e.g., Fig. 3). 
The shear stress evolution in Fig. 5A indicates that during the sticking phase there is an elastic stage, a yielding point of transfer to a creep stage, up to the peak stress, which is followed by the slip phase. This evolution is practically the same as in typical rock-mechanics experiment (Fig. 5B) with a sequence of linear-elastic, yield point and strain-hardening to the ultimate strength (e.g., Wawersik and Brace, 1971). Further, the macroscopic peak values of the shear-stress and normal-stress during slip initiation display a linear Coulomb-Mohr relationship as shown in Fig. 5C for both SWG and RNG. These relationships are similar to the failure relationships of brittle rocks, indicating that the stick-slip event is a solid asperity failure as hypothesized in the present model (Fig. 2). Finally, we noted a style difference between the stick-slips along the SWG and the RNG faults (Fig. 3 and text). This style difference can be attributed to differences in the mechanical properties, e.g., gabbro being stronger and more brittle, and to the fault surface quality. The relatively lower brittleness of granite is manifested by the early appearance of a yield point followed by a long stage of strain hardening (Fig. 5A, B), in contrast to the long elastic stage and a short strain hardening stage of the gabbro (Fig. 3A).

However, the magnitudes of the peak stresses of the stick-slips (Fig. 5C) are significantly smaller than the corresponding stresses of rock failure, which are in the range of hundreds of MPa, e.g, Fig. 5B (Lockner, 1995). This apparent contrast reflects the geometry of fault surface: The real contact area, $A_{a}$, of the locked asperities is only a small fraction of the nominal area, $A_{0}$, and therefore, the measured, macroscopic stresses are also small. Tabor (1981, Fig. 7) found that on metal surfaces, which were prepared with an engineering finish, the real contact area is $A_{a} / A_{0}$ $=\sigma_{\mathrm{n}} / S_{T}$ where $S_{T}$ is the plastic strength of the metal, and that cyclical normal loading may increase the contact area to $\mathrm{A}_{\mathrm{a}} / \mathrm{A}_{0}=(3 \sim 10) \cdot \sigma_{\mathrm{n}} / S_{T}$. We modify this relationship of Tabor (1981) by replacing the normal-stress with the measured shear-stress, and by replacing the plastic strength $S_{T}$ with the inherent shear strength of granite $S_{I} \sim 1,000 \mathrm{MPa}$ (Savage et al., 1996, above). The resulting relationship for the present model is

$$
\mathrm{A}_{\mathrm{a}} / \mathrm{A}_{0}=(3 \sim 10) \cdot \tau / S_{I}
$$

We now substitute into the last equation the macroscopic shear stress of $\tau=4-10 \mathrm{MPa}$ (Fig. 5C), and the assumed strength of the touching asperities, $S_{I}=1,000 \mathrm{MPa}$ (after Savage et al., 1996), and find that the corresponding range of contact area ratio is $A_{a} / A_{0}=0.012-0.1$. This range of contact area ratio is in general agreement with the findings of Dieterich and Kilgore (1996) for 
quartz and calcite under normal stress of $\sigma_{\mathrm{n}}=30 \mathrm{MPa}$ (Fig. 1D). A similar approach was used by Svetlizky and Finberg (2014) who compared the fracture energy of shear along a rough PMMA fault $\left(1.1 \mathrm{Jm}^{-1}\right)$ to the bulk fracture energy of PMMA $\left(2,000 \mathrm{Jm}^{-1}\right)$, and found that in their case, the calculated contact area ratio of $\mathrm{A}_{\mathrm{a}} / \mathrm{A}_{0}=1.1 / 2,000 \sim 0.005$.
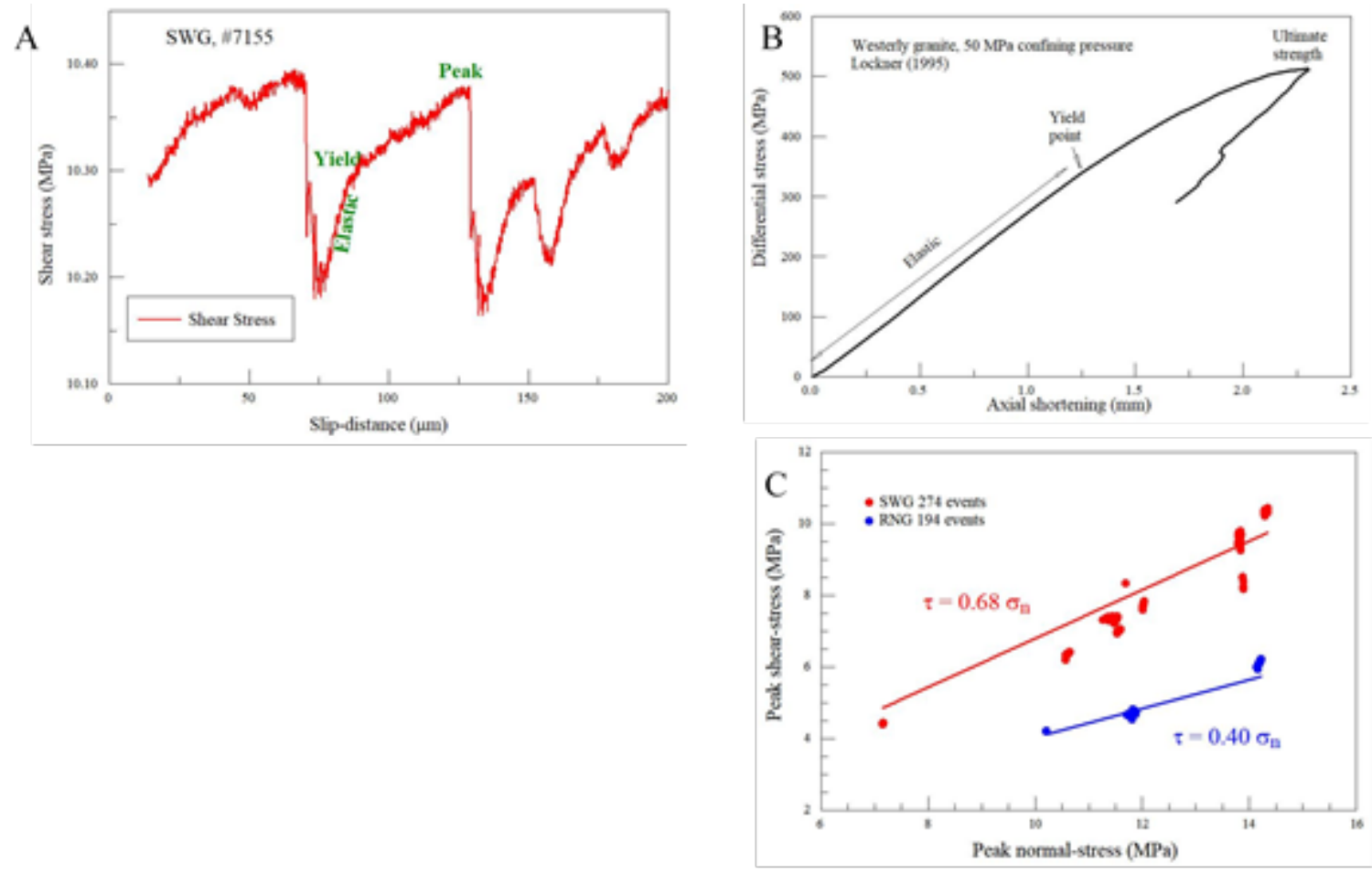

Figure 5. Loading and failure in stick-slip and rock-mechanics experiments. A. Shear stress as a function of slip distance during four stick-slip events along SWG (experiment 7155, detail of Fig. 3B). B. Differential stress as function of axial shortening during failure experiment of Westerly granite under servo-control (after Lockner, 1995); note similarity of failure stage with the stickslip event in A. C. Mohr diagram for peak stresses of the analyzed stick-slip experiments.

In the above paragraph, we argue that for $\mathrm{A}_{\mathrm{a}} / \mathrm{A}_{0}=0.012-0.1$, the local stresses at the touching asperities in our experiments are approximately equal to the inherent strength of the tested rocks, $S_{I}$. As the slip along the experimental fault requires asperity failure, we conclude that the asperities strength of equation $(1), U_{\mathrm{i}} \approx S_{I}$. Again, the failure of the asperities is supported by the common observation that isolated asperities are pulverized into fine-grain powder even under small slip distance and low slip velocity (Fig. 1) (Byerlee, 1966; Boneh et al., 2014). This local pulverization indicates brittle fragmentation of the touching asperities as assumed in the model (Fig. 2). 


\subsection{SLIP-DISPLACEMENT AND STRESS-DROP}

In our experiments, we continuously monitored the displacement, $D_{m}$, between the two fault blocks by using an eddy current sensor with sub-micron resolution (Boneh et al., 2014). This sensor was mounted away from the fault, and measured the relative block displacement at distance of $\sim 3 \mathrm{~cm}$ from either side of the fault as shown in Figs. A1B, C. The slip-displacement along the fault during a stick-slip is evaluated as follows. The stick-slip event is driven by the elastic relaxation of the entire loading system (equation 2) that includes the sample and the apparatus (Lockner et al., 2017). During an event, $D_{m}$, is measured between two monitoring points $\sim 3 \mathrm{~cm}$ away from the fault (Fig. A1B), and thus it includes only the relaxation component of the rock sample; however, the relaxation component of the apparatus, away from the monitoring points is not accounted (analogous to Lockner et al., 2017, there Fig. 6.1 and equation 6.2). This second component of apparatus relaxation is difficult to evaluate, and we use $D_{m}$ as a conservative estimate of stick-slip displacement, $D_{i}$, during the $\mathrm{i}^{\text {th }}$ event (equation 2). The plot of the measured $\Delta \tau_{\mathrm{i}}$ as function of measured $D_{i}$ for the $280 \mathrm{SWG}$ stick-slip events (Fig. 6A) shows that $\Delta \tau_{\mathrm{i}}=0.12 D_{i}$. Namely, the effective elastic stiffness of the loading system is $0.12 \mathrm{MPa} / \mu \mathrm{m}$ which is larger than the independently measured stiffness of $0.088 \mathrm{MPa} / \mu \mathrm{m}$ (above); this difference may be attributed to the apparatus relaxation component mentioned above.

In the present model (Fig. 2), the slip-displacement during an event is controlled by the distance, $D_{i}$, between the lock-and-fail asperity $\# 1$, and the new locking asperity \#2 (Fig. 2). Thus, the distances between the asperities determine the slip-distances and as a consequence, the distances also determine the stress-drops (equations 2, 5). We measure the distances between the peaks of the high asperities in three of the AFM maps of the SWG (see Appendix for details). We assume that the lock-and-fail mechanism operates between high asperities, and compare the frequency distribution of the measured distances (blue curve in Fig. 6B) with the frequency distribution of the slip-displacement during the SWG stick-slip event (red curve in Fig. 6B). The distribution curves have similar shapes shifted by $\sim 1 \mu \mathrm{m}$; this shift may reflect the sampling of only the highest asperities, whereas lower asperities could also participate in the lock-and-fail process. This similarity between these two independent measurements supports the model assumption that the slip-displacement is controlled by the high, touching asperities. 

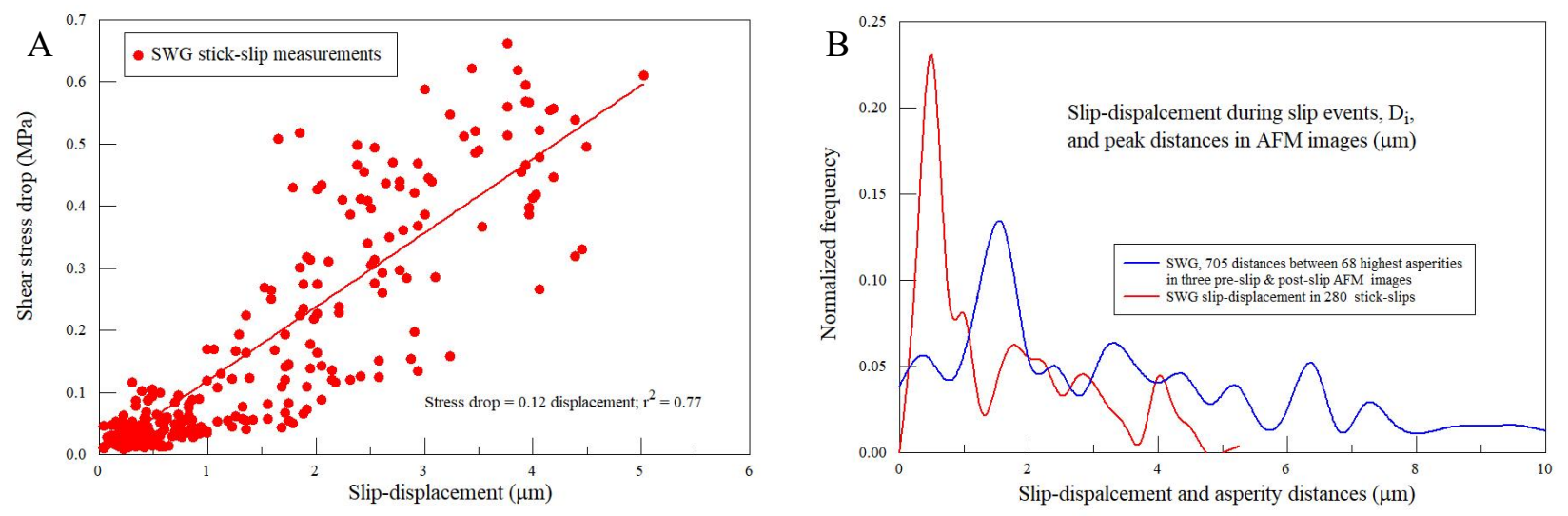

Figure 6. Slip-displacements, stress-drops, and surface roughness in SWG experiments. A.

Measured stress-drop as function of measure slip-displacement of 280 stick-slip events along the SWG fault (see text). B. Frequency distribution of 705 distances between high asperities in Fig. A2A-C (blue curve), and frequency distribution of slip-displacements in 280 stick-slip events (red curve) (see Appendix).

\section{Discussion}

\subsection{STICK-SLIPS AS A FRACTURE PROCESS}

The present analysis considers stick-slips along bare, flat rock faults. The real contact area of such a fault is at isolated, touching asperities that cover $0.1-2.0 \%$ of the nominal area (Fig. 2, 4) (Dieterich and Kilgore, 1996). Only the touching asperities can resist slip along the fault while the non-touching spaces between the isolated asperities do not contribute to the slip resistance. Inspection of the surfaces of bare, flat rock faults has systematically revealed elongated striations of smeared powder of fragmented, isolated asperities (Fig. 1) (Scholz and Engelder, 1976; Boneh et al., 2014; Yamashita et al., 2018; Tesei et al., 2017; Boneh and Reches, 2018). Therefore, the central concept here is that slip along a brittle experimental fault initiates when touching asperities fail by fracturing. Brace and Byerlee (1966) explored "Stick-slip as a mechanism for earthquakes" by testing Westerly granite samples which were either intact or with an initial sawcut. Their experiments revealed jerky, irregular stick-slips (their Fig. 1) under high confining pressure (up to $650 \mathrm{MPa}$ ) while generating similar stick-slips for both intact samples and saw-cut samples. This similarity suggests that 'frictional slip' along a saw-cut sample is essentially controlled by fracturing. 
Brittle fracturing of isolated, contacting asperities is considered here as the controlling process of stick-slips, yet, the contact area evolution could not be monitored in the opaque rock samples. This limitation can be removed in shear experiments with fault composed of transparent brittle polymer (PMMA) (Rubinstein et al., 2011; Svetlizky and Fineberg, 2014). Svetlizky and Fineberg (2014) analyzed stick-slip ruptures along a planar PMMA interface and found that the strain fields around the rupture front perfectly fits the theoretical strain field of a rapid, mode II fracture (Freund, 1990). They also found that the linear weakening slip-displacement at the rupture front is about $1.4 \mu \mathrm{m}$, which is compatible with interface roughness of $\sim 3 \mu \mathrm{m} \mathrm{rms}$. This analysis was furthered by Bayart et al. (2016) who focused on rupture arrest and the slip-distance associated with experimental stick-slips. They stated that the "results provide clear evidence that frictional rupture is really a fracture process that can be quantitatively described by fracture mechanics. The concepts presented here suggest a completely different paradigm for understanding friction from that of the classical picture, which is based on the balance of local forces (stresses)."

While the PMMA experiments indicate that dynamic rupture is a fracture phenomenon, and the present rock experiments are consistent with brittle asperity fracturing, stick-slip behavior is almost universally analyzed in terms of static and dynamic friction coefficients (e.g., Karner and Marone, 2000). The friction coefficient is an easily measured parameter, but it carries no direct physical mechanism. We thus argue that while the usage of friction coefficient(s) is convenient, the mechanics of fracturing provides a clearer insight to stick-slip processes.

\subsection{APPLICATION TO GRANULAR LAYERS AND GOUGE-FILLED FAULTS}

In the present analysis, we consider an experimental fault composed of a planar, rough, bare rock surface (Fig. 2), along which the local stress amplification is controlled by touching asperities. We infer, however, that the derived mechanics may be valid to other configurations in which local failure leads to macroscopic stick-slips, for example, along experimental faults with a gouge layer. We outline below two failure mechanisms within a gouge layer that are compatible with the present stick-slip mechanics.

The first failure mechanism is based on the 'effective asperity' concept developed by Boneh and Reches (2018) in their analysis of brittle wear along fault with a gouge layer (Fig. 7A). In this case, the fracturing which occurs at the contact between the gouge layer and the fault blocks 
(Lyakhovsky et al., 2014) modifies the contact roughness and forms new large particles, defined as 'effective asperities' (Boneh and Reches, 2018). While these new asperities differ in shape and size from the originals (Fig. 7A), they also amplify the local stresses because they do not deform as easily as the surrounding gouge. The amplified local stresses are expected to lead to intense local fracturing, including sub-surface fracturing of the rock blocks (Fig. 7A) (Lyakhovsky et al., 2014). If this local fracturing occurs unstably, it would generate macroscopic stick-slips in a similar style to the present mechanism.

Another mechanism that can generate stick-slips is the unstable failure of highly stressed force-chains within a granular layer. It is well documented, both experimentally and numerically, that shear loading of a granular layer is supported mostly, if not completely, by a network of isolated force-chains (Fig. 7B) (e.g. Majmudar and Behringer, 2005). With continuous shear, the fault with the granular layer exhibits macroscopic stick-slips that most analysis attribute to unstable collapse of the force-chains (e.g. Scuderi et al., 2014), while usually the experiments are designed to limit the possible fracturing of the grains. However, we envision that the highly stressed grains are very susceptible to brittle fracturing and thus propose that stick-slips along faults with a granular layer are controlled by local, brittle fracturing within the isolated stresschains. We further suggest that the mechanics of the associated stick-slip would fit the framework of the present model.
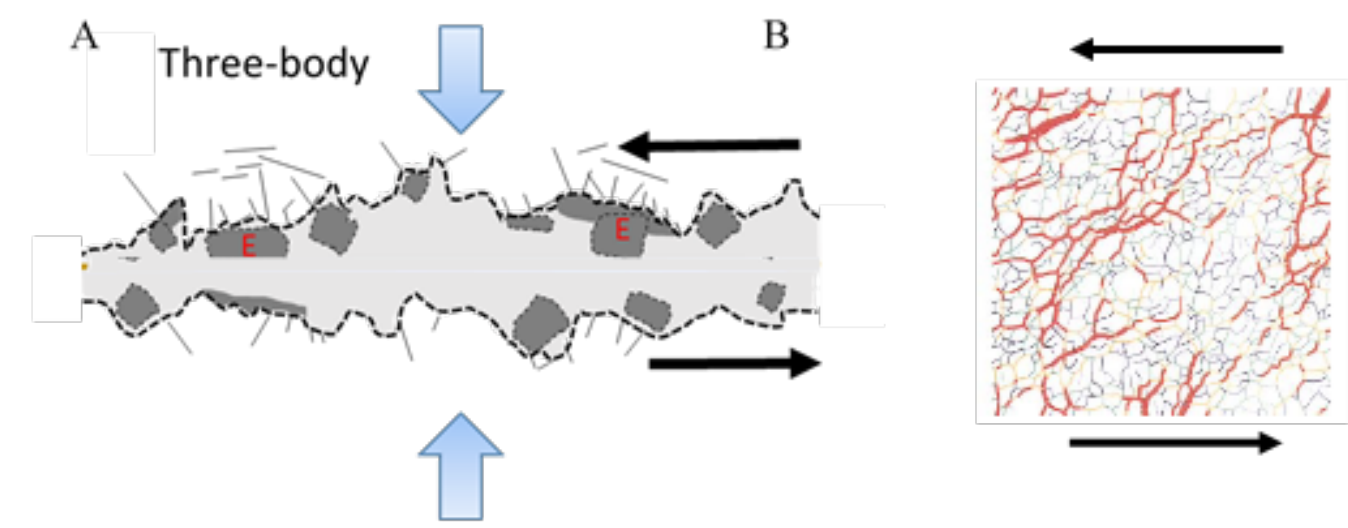

Figure 7. A. A fault with a gouge layer (light grey) that includes large, coarse grains (dark grey) which act like effective asperities with increased local stress (after Boneh and Reches, 2018). B. Simulated stress field within a granular layer subjected to shear; the grains contacts are not shown; line thickness is scaled to the largest stress (after Aharonov and Sparks, 2002). 


\section{Conclusions}

The present analysis of brittle fracturing of isolated asperities provides significant insight into a few distinct features of experimental stick-slip behavior.

A. We evaluate the strength of fault asperities as 400-1,000 MPa based on the experimental shear and normal stresses and the contact area of touching asperities (Fig. 5). This strength is in the range of the inherent shear strength of intact, perfect rock (Savage et al., 1996). The inherent strength reflects the local stress-state of the failing asperity.

B. In the present analysis, we applied the material hardness, $\mathrm{H}$, as an effective variable in characterization of fracture tendency of fault asperities (Tables 1, 2). Hardness is measured at small scales, which are relevant to the asperities' size, and it integrates multiple failure properties.

C. The analysis explains why fragmentation and wear can be reduced by surface smoothing that reduces the asperities inclination, $\theta$, and increases the real contact area, $A_{a}$; both these geometric features reduce local stresses and fracture tendency. Further, as dissipation of fracture energy is a contribution component to frictional resistance (Boneh et al., 2014), smoother rock surfaces, with less fracturing, would display lower friction coefficients (Chen et al., 2013).

D. According to the present model, the stress-drop during stick-slip is determined by the distances between locking asperities, and controlled by the system stiffness (Figs. 2, 6). This inference could have significant implications to fault behavior. The distances between potentially locking asperities depend on fault roughness. As these distances are larger on a smooth fault, it is anticipated that a smooth fault will generate more intense (stress-drop and slip-distance) stick-slips than a rough fault in the same system (e.g., Ohnaka, 1973). We thus speculate that quantification of fault roughness in terms of both power spectral density (Fig. 6C) and local slope (Fig. 4) could predict the intensity of the stick-slips.

\section{ACKNOWLEDGMENTS}

Many thanks for the discussions with Einat Aharonov and Jay Fineberg. The insightful comments of two anonymous reviewers led to significant improvements of the presentation. The research was funded by NSF grant EAR-1620330 "Investigating earthquake source processes in 
the laboratory" and NSF grant EAR-1345087 "Experimental simulation of earthquake rupture processes". Additional data including programs and materials will become available upon request for reproducing or extending the analysis. The authors declare no conflict of interests.

Table 1. Rock mechanical properties and calculated critical asperity slope for brittle failure.

\begin{tabular}{|l|c|c|c|c|}
\hline $\begin{array}{l}\text { Rock/mineral/ } \\
\text { material }\end{array}$ & $\begin{array}{c}\text { Modulus } \\
\mathrm{E}, \mathrm{GPa}\end{array}$ & $\begin{array}{c}\text { Hardness } \\
\mathrm{H}, \mathrm{GPa}\end{array}$ & $\mathrm{E} / \mathrm{H}$ & $\begin{array}{c}\text { Critical } \\
\text { angle }\end{array}$ \\
\hline Granite & $38-75^{\mathrm{a}}$ & $8.8-11.4^{\mathrm{d}}$ & $3-8$ & $>7^{\circ}-17^{\circ}$ \\
\hline Gabbro & $50-115^{\mathrm{b}}$ & $12-15^{\mathrm{d}}$ & $3-9$ & $>6^{\circ}-19^{\circ}$ \\
\hline Quartz & $14.5^{\mathrm{c}}$ & & \\
\hline Orthoclase & $9.1^{\mathrm{c}}$ & & \\
\hline Calcite & $2.2^{\mathrm{c}}$ & & \\
\hline Pure metal (annealed) & & $200-400^{\mathrm{e}}$ & $>0.5^{\circ}$ \\
\hline Ceramic & $20-30^{\mathrm{e}}$ & $5^{\circ}$ \\
\hline Cross-linked plastics & $3-5^{\mathrm{e}}$ & $>20^{\circ}$ \\
\hline
\end{tabular}

a- Katz et al. (2000)

b- Keshavarz et al. (2010)

c- Broz et al. (2006)

d- Estimated from Broz et al. (2006)

e- Critical strength/slope for plastic deformation, Tabor (2006)

Table 2. Summary of AFM surface characterization (Fig. 4 and Appendix)

\begin{tabular}{|l|l|c|c|}
\hline \multicolumn{2}{|c|}{} & \multicolumn{2}{c|}{ Slopes (for upper half) } \\
\cline { 3 - 4 } \multicolumn{2}{|c|}{} & fraction $>6^{\circ}$ & fraction $>17^{\circ}$ \\
\hline \multirow{2}{*}{ Granite } & pre-shear & $90 \% \pm 4 \%$ & $54 \% \pm 16 \%$ \\
\cline { 2 - 4 } & post-shear & $74 \% \pm 12 \%$ & $25 \% \pm 15 \%$ \\
\hline Diorite & pre-shear & $87 \% \pm 1 \%$ & $48 \% \pm 6 \%$ \\
\hline Gabbro & post-shear & $79 \% \pm 3 \%$ & $35 \% \pm 6 \%$ \\
\hline
\end{tabular}




\section{APPENDIX}

\section{EXPERIMENTAL SET-UP}

The high-velocity, rotary shear apparatus (ROGA) (Reches and Lockner, 2010) was modified to include an integrated low-velocity capability driven by a stepper motor for slip-velocities of $0.25 \mu \mathrm{m} / \mathrm{s}$ to $1 \mathrm{~mm} / \mathrm{s}$ (item 4 in Fig. A1A). The experimental fault has a ring-shaped contact between a lower solid rock blocks (10.2 cm diameter and $5 \mathrm{~cm}$ height) and an upper block with raised ring (Fig. A1B). The gabbro fault has inner diameter of $62 \mathrm{~mm}$ and outer diameter of $\sim 84$ $\mathrm{mm}$, while the SWG fault has inner diameter of $61.4 \mathrm{~mm}$ and outer diameter of $84.5 \mathrm{~mm}$. Bare rock surfaces with \#600 grit roughening were used for the present tests. Rotation is applied to the lower block by the stepper motor and the upper block is stationary; the velocity and displacement were controlled by this stepper motor. The mechanical data were monitored at rates of 3,0005,000 samples/s, and included the normal and shear stresses by load cells, and the displacement between the two fault blocks by an eddy current sensor (Fig. A1B, C). Acoustic emissions were monitored by $3 \mathrm{D}$ accelerometers at rate of $1 \mathrm{MHz}$ for periods up to $4 \mathrm{sec}$ for part of the run durations. The experimental data were continuously recorded with a dedicated Labview program at sampling rate of $3 \mathrm{k}-5 \mathrm{k} \mathrm{Hz}$.

\section{EXPERIMENTAL PROCEDURE}

The typical procedure for the shear experiments includes the following steps. First, load the sample, attach the displacement sensor. Second, set and apply the desired normal stress on the fault. Third, use the stepper motor system to load the fault at desired velocity and duration. Typical driving speed is $1-10 \mu \mathrm{m} / \mathrm{s}$, and typical loading duration is $10-20 \mathrm{~s}$. The normal stress was kept constant during the shear and can be adjusted in between shear. Experiments ran at lower normal stresses, $\sigma_{\mathrm{n}}<10.5 \mathrm{MPa}$, slide stably without any stick-slips for both SWG and RNG faults; these experiments are not reported here. At higher normal stresses, stick-slips start to occur. The experimental conditions and results summery are listed in Table A1. 

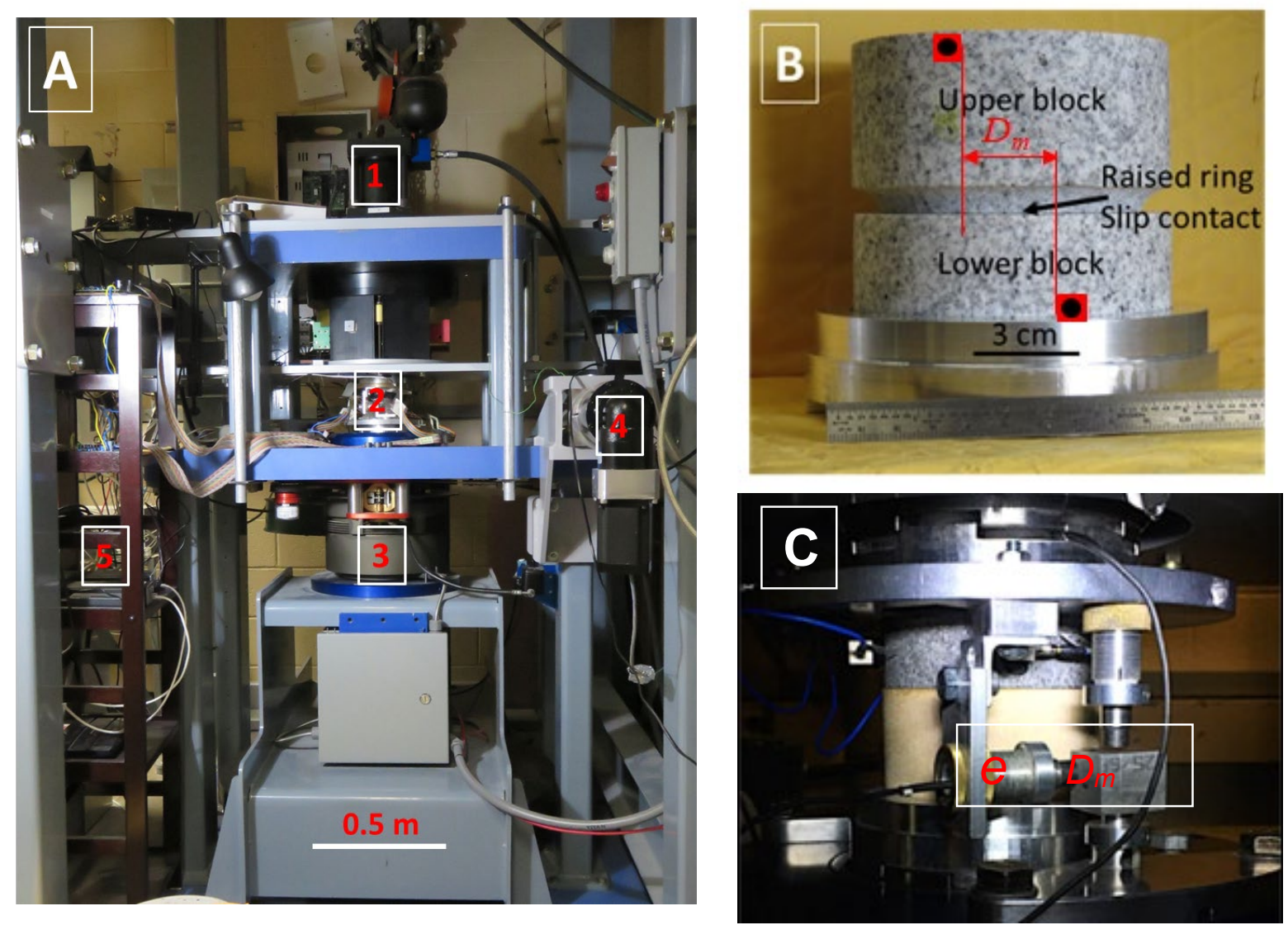

Figure A1. The ROGA apparatus (Reches and Lockner, 2010). A. The apparatus with marked load cell (1), sample loading site (2), electric-magnetic clutch (3), step motor arm for low velocity tests (4), and high-frequency strain-gauge sampling hardware for rupture propagation monitoring (5). B. The fault rock samples of SWG with schematic presentation of the measuring slip, $D_{m}$, between top and bottom of the fault blocks. C. Photo of a bi-material fault with a horizontal eddy-current sensor (e) and location of $D_{m}$.

\section{AFM MAPPING OF FAULT SURFACES}

We used AFM (atomic force microscope) from Asylum Research to map topography of both the pre-shear rock surface and the post-shear fault surface. The topologic images were acquired under the AC mode (tapping) in ambient room conditions, with typical scan area of a few $\mu \mathrm{m}$ up to $60 \mu \mathrm{m}$ across with resolution up to 1024 by 1024 pixels. We mapped 6 polished pre-shear surfaces and 13 post-shear surfaces from SWG, 4 post-shear surfaces from gabbro, and 4 preshear surfaces from a diorite as an approximate to gabbro (no available pre-shear gabbro surface 
for AFM). Typical maps are displayed in Fig. 4. The two-dimensional height distribution and surface inclination distribution (Fig. 4E, F) are extracted from the AFM topographic map using the Gwyddion software available online (http://gwyddion.net).

We measure the distances between the peaks of the highest asperities in three of the AFM maps of SWG. The peaks of the highest asperities were first digitized (white points in Fig. A2) and then the distances were calculated. In the pre-shear maps (Fig. A2A, B) the distances were calculated between all marked highest asperities (note scales of maps). In the post-slip map (Fig. A2C), which displays clear slip striations, the asperity distances were calculated between neighboring marked high asperities; we assume that the lock-and-fail mechanism operates only parallel to the slip direction. Note that the used images display the upper $50 \%$ of the surface elevation and the lower $50 \%$ is colored black.
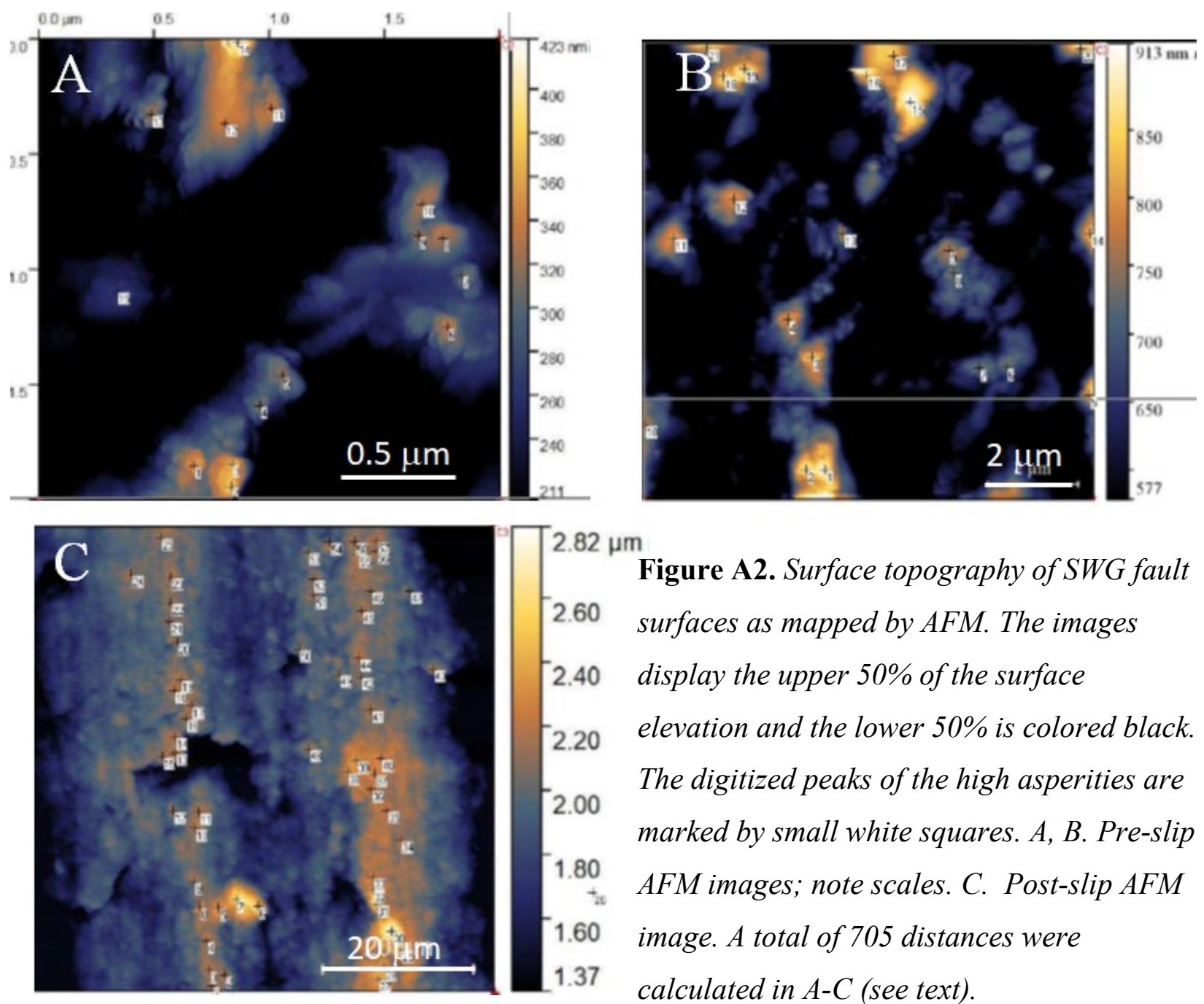

Figure A2. Surface topography of SWG fault surfaces as mapped by AFM. The images display the upper $50 \%$ of the surface elevation and the lower $50 \%$ is colored black. The digitized peaks of the high asperities are marked by small white squares. A, B. Pre-slip AFM images; note scales. C. Post-slip AFM image. A total of 705 distances were calculated in $A-C$ (see text). 
Table A1. Experimental conditions and summary of main results

\begin{tabular}{|c|c|c|c|c|c|c|c|c|}
\hline & \multirow{3}{*}{$\underset{\#}{\text { Run }}$} & \multirow{3}{*}{$\begin{array}{c}\begin{array}{c}\text { Normal } \\
\text { stress }\end{array} \\
\mathrm{MPa}\end{array}$} & \multirow{3}{*}{$\begin{array}{c}\text { Applied } \\
\text { velocity }\end{array}$} & \multirow{3}{*}{$\begin{array}{c}\# \\
\text { events }\end{array}$} & \multicolumn{4}{|c|}{ Event Ranges } \\
\hline & & & & & stress drop & displacement & rise time & max velocity \\
\hline & & & & & $\mathrm{MPa}$ & $\mu \mathrm{m}$ & $\mathrm{ms}$ & $\mu \mathrm{m} / \mathrm{s}$ \\
\hline \multirow{22}{*}{$\begin{array}{l}\text { Sierra } \\
\text { White } \\
\text { granite }\end{array}$} & 7152 & 14.3 & 308 & 10 & $0.024-0.04$ & $0.73-1.80$ & $1-1.6$ & $726-1,040$ \\
\hline & 7154 & 14.3 & 185 & 7 & $0.065-0.081$ & $1.26-2.19$ & $1-1.2$ & $875-1,172$ \\
\hline & 7155 & 14.3 & 617 & 21 & $0.043-0.158$ & $1.72-5.02$ & $1.2-1.6$ & $1,057-3,451$ \\
\hline & 7160 & 13.9 & 617 & 41 & $0.038-0.512$ & $1.41-9.16$ & $0.6-1.5$ & $1,321-12,177$ \\
\hline & 7161 & 13.8 & 62 & 20 & $0.069-0.387$ & $1.21-6.68$ & $0.75-1$ & $1,770-7,423$ \\
\hline & 7162 & 13.8 & 62 & 14 & $0.04-0.619$ & $1.04-10.86$ & $0.75-1.25$ & $1,057-13,076$ \\
\hline & 7163 & 13.8 & 185 & 44 & $0.033-0.663$ & $0.83-11.92$ & $0.75-1.5$ & $1,162-14,159$ \\
\hline & 7164 & 13.7 & 19 & 8 & $0.06-0.170$ & $1.31-3.14$ & $0.75-0.88$ & $1,400-4,755$ \\
\hline & 7165 & 13.8 & 19 & 3 & $0.034-0.042$ & $0.65-0.83$ & 0.75 & $1,057-1,506$ \\
\hline & 7166 & 13.8 & 185 & 13 & $0.046-0.314$ & $1.07-6.09$ & $0.75-1$ & $1,426-7,053$ \\
\hline & 7416 & 10.6 & 308 & 5 & $0.015-0.022$ & $0.31-0.43$ & $0.6-0.8$ & $188-3,944$ \\
\hline & 7417 & 10.5 & 308 & 12 & 0.01-0.020 & $0.09-0.67$ & $0.6-1.2$ & $562-3,569$ \\
\hline & 7419 & 11.5 & 308 & 13 & $0.009-0.045$ & $0.22-1.18$ & $0.4-0.8$ & $376-3,193$ \\
\hline & 7430 & 11.3 & 62 & 3 & $0.013-0.028$ & $0.22-0.41$ & $0.6-0.8$ & $564-7,50$ \\
\hline & 7431 & 11.3 & 617 & 2 & $0.025-0.028$ & $0.22-0.36$ & 0.6 & 376 \\
\hline & 7432 & 11.3 & 617 & 7 & $0.012-0.058$ & $0.33-1.03$ & $0.6-0.8$ & $374-, 1691$ \\
\hline & 7433 & 11.4 & 617 & 8 & $0.017-0.055$ & $0.17-1.09$ & $0.4-1.2$ & $188-1,127$ \\
\hline & 7434 & 11.4 & 617 & 15 & $0.012-0.052$ & $0.23-0.72$ & $0.4-0.8$ & $188-1,435$ \\
\hline & 7435 & 11.5 & 617 & 7 & $0.016-0.026$ & $0.24-0.52$ & $0.6-1.2$ & $188-1,435$ \\
\hline & 7436 & 11.5 & 617 & 19 & $0.015-0.116$ & $0.24-1.05$ & $0.4-1$ & $188-1,691$ \\
\hline & 7460 & 11.6 & 617 & 2 & $0.013-0.017$ & $0.63-0.66$ & 0.6 & $940-1,128$ \\
\hline & 7464 & 12.0 & 617 & 7 & $0.029-0.063$ & $0.82-1.16$ & $0.6-0.8$ & $1503-2,067$ \\
\hline \multirow{15}{*}{$\begin{array}{l}\text { Raven } \\
\text { Noir } \\
\text { gabbro }\end{array}$} & 7298 & 11.8 & 9.54 & 103 & $0.053-0.114$ & $4.25-5.75$ & $147-270$ & $28-49$ \\
\hline & 7299 & 11.7 & 9.54 & 10 & $0.068-0.081$ & $4.02-5.15$ & $192-206$ & $32-38$ \\
\hline & 7300 & 11.8 & 1.03 & 16 & $0.268-0.458$ & $9.65-15.91$ & $207-360$ & $129-235$ \\
\hline & 7301 & 11.8 & 0.26 & 10 & $0.345-0.477$ & 12.17-17.58 & $110-340$ & $184-257$ \\
\hline & 7302 & 11.8 & 0.26 & 3 & $0.155-0.196$ & $3.59-4.82$ & $286-350$ & $30-46$ \\
\hline & 7304 & 11.8 & 0.26 & 5 & $0.357-0.598$ & $7.38-12.23$ & $244-496$ & $97-162$ \\
\hline & 7305 & 11.8 & 0.52 & 6 & $0.312-0.411$ & $6.44-8.41$ & $218-412$ & $80-116$ \\
\hline & 7306 & 11.8 & 1.03 & 7 & $0.254-0.421$ & $5.35-8.46$ & 233-380 & $61-128$ \\
\hline & 7307 & 11.9 & 2.06 & 7 & $0.186-0.391$ & $3.82-8.13$ & $133-284$ & $42-113$ \\
\hline & 7308 & 11.9 & 3.87 & 9 & $0.122-0.416$ & $3.25-8.66$ & $101-243$ & $29-128$ \\
\hline & 7316 & 14.2 & 3.87 & 9 & $0.125-0.473$ & $4.66-12.9$ & $103-268$ & $29-200$ \\
\hline & 7318 & 14.2 & 1.03 & 4 & $0.328-0.332$ & $7.70-7.80$ & 287-339 & $94-100$ \\
\hline & 7319 & 14.2 & 0.52 & 7 & $0.381-0.479$ & $8.98-10.74$ & $300-446$ & $115-153$ \\
\hline & 7320 & 14.2 & 0.26 & 6 & $0.435-0.506$ & 10.34-11.95 & $555-755$ & $151-185$ \\
\hline & 7321 & 10.2 & 0.26 & 7 & $0.307-0.372$ & $8.91-10.67$ & $505-780$ & $125-169$ \\
\hline
\end{tabular}




\section{REFERENCES}

Aharonov, E., Sparks, D., 2002. Shear profiles and localization in simulations of granular materials. Physical Review E, 65(5), 051302. doi:10.1103/PhysRevE.65.051302.

Bayart, E., Svetlizky, I., Fineberg, J., 2016. Fracture mechanics determine the lengths of interface ruptures that mediate frictional motion. Nature Physics, 12, 166-170. doi:

10.1038/nphys3539.

Boneh, Y., Chang, J. C., Lockner, D. A., Reches, Z., 2014. Evolution of wear and friction along experimental faults. Pure and Applied Geophysics, 171, 3125-3141. doi: 10.1007/s00024014-0801-3.

Boneh, Y., Reches, Z., 2018. Geotriboloty - Friction, wear, and lubrication of faults. Tectonophysics, 733, 171-181. doi:10.1016/j.tecto.2017.11.022.

Brace, W. F., Byerlee J. D., 1966. Stick-slip as a mechanism for earthquakes. Science, 153, 990992. doi:10.1126/science.153.3739.990.

Broz, M. E., Cook, R. F., Whitney, D. L., 2006. Microhardness, toughness, and modulus of Mohs scale minerals. American Mineralogist, 91(1), 135-142. doi:10.2138/am.2006.1844.

Byerlee, J. D., 1967. Frictional characteristics of granite under high confining pressure. Journal of Geophysical Research, 72, 3639-3648. doi:10.1029/JZ072i014p03639.

Byerlee, J. D., 1970. The mechanics of stick-slip. Tectonophysics, 9, 475-486. doi:10.1016/00401951(70)90059-4.

Chen, X., Madden, A. S., Bickmore, B. R., Reches, Z., 2013. Dynamic weakening by nanoscale smoothing during high-velocity fault slip. Geology, 41, 739-742. doi:10.1130/G34169.1.

Das, S., Kostrov, B. V., 1986. Fracture of a single asperity on a finite fault: A model for weak earthquakes?. Earthquake Source Mechanics, 37, 91-96.

Di Toro, G., Han, R., Hirose, T., De Paola, N., Nielsen, S., Mizoguchi, K., Shimamoto, T., 2011. Fault lubrication during earthquakes. Nature, 471, 494-498. doi:10.1038/nature09838.

Dieterich, J. H., 1978. Time-dependent friction and the mechanics of stick-slip. Pure and Applied Geophysics, 116, 790-806. doi:10.1007/978-3-0348-7182-2_15.

Dieterich, J. H., Kilgore, B. D., 1996. Imaging surface contacts: power law contact distributions and contact stresses in quartz, calcite, glass, and acrylic plastic. Tectonophysics, 256, 219239. doi:10.1016/0040-1951(95)00165-4.

Engelder, J. T., Scholz, C. H., 1976. The role of asperity indentation and ploughing in rock friction - II: Influence of relative hardness and normal load. International Journal of Rock Mechanics and Mining Sciences \& Geomechanics Abstracts, 13, 155-163. doi:10.1016/01489062(76)90820-2.

Freund, L. B. Dynamic Fracture Mechanics, Cambridge, 1990.

Greenwood, J. A., Williamson, J. B. P., 1966. Contact of nominally flat surfaces. Proceedings of the Royal Society A. 295, 300-319. doi:10.1098/rspa.1966.0242.

Hirth, J.P., and Lothe, J., 1968. Theory of Dislocations, 780 pp., McGraw-Hill, New York.

Jaeger, J. G., Cook, N. G. W., 1969. Fundamentals of rock mechanics. Methuen, London.

Karner, S., Marone, C., 2000. Effects of loading rate and normal stress on stress drop and stickslip recurrence interval. in Rundle, J., Turcotte, D., \& Klein, W. eds. Geocomplexity and the physics of Earthquakes. AGU Geophysical Monograph 120, 187-198. doi:10.1029/GM120p0187. 
Katz, O., Reches, Z., Roegiers, J. C., 2000. Evaluation of mechanical rock properties using a Schmidt Hammer. International Journal of rock mechanics and mining sciences, 37(4), 723 728. doi:10.1016/S1365-1609(00)00004-6.

Keshavarz, M., Pellet, F. L., Loret, B., 2010. Damage and changes in mechanical properties of a gabbro thermally loaded up to $1,000^{\circ} \mathrm{C}$. Pure and Applied Geophysics, 167, 1511-1523. doi:10.1007/s00024-010-0130-0.

Koizumi, Y., Otsuki, K., Takeuchi, A., Nagahama, H., 2004. Frictional melting can terminate seismic slips: Experimental results of stick-slips. Geophysical Research Letters, 31, L21605. doi:10.1029/2004GL020642.

Leeman, J. R., Marone, C., Saffer, D. M., 2018. Frictional mechanics of slow earthquakes. Journal of Geophysical Research: Solid Earth, 123, 7931-7949. doi:10.1029/2018JB015768.

Lockner, D. A., 1995. Rock failure, in Ahrens, T. J. ed. Rock physics \& phase relations: a handbook of physical constants, Volume 3. 127-147. doi: 10.1029/RF003p0127.

Lockner, D. A., Kilgore, B. D., Beeler, N. M., \& Moore, D. E. (2017). The transition from frictional sliding to shear melting in laboratory stick-slip experiments. Fault zone dynamic processes: Evolution of fault properties during seismic rupture, 105-132.

Lyakhovsky, V., Sagy, A., Boneh, Y., Reches, Z., 2014. Fault wear by damage evolution during steady-state slip. Pure and Applied Geophysics, 171(11), 3143-3157. doi:10.1007/s00024014-0787-x.

Majmudar, T.S., Behringer, R.P., 2005. Contact force measurements and stress-induced anisotropy in granular materials. Nature, 435, 1079. doi:10.1038/nature03805.

McLaskey, G. C., Glaser, S.D., 2011. Micromechanics of asperity rupture during laboratory stick slip experiments. Geophysical Research Letters, 38.12.

Niemeijer, A., Di Toro, G., Nielsen, S., Di Felice, F., 2011. Frictional melting of gabbro under extreme experimental conditions of normal stress, acceleration, and sliding velocity. Journal of Geophysical Research,116, B07404. doi:10.1029/2010JB008181.

Ohnaka, M. 1973. A physical understanding of the earthquake source mechanism. Journal of Physics of the Earth, 21, 39-59. doi: 10.4294/jpe1952.21.39.

Ohnaka, M., Kuwahara, Y., Yamamoto, K., 1987. Constitutive relations between dynamic physical parameters near a tip of the propagating slip zone during stick-slip shear failure. Tectonophysics, 144, 109-125. doi:10.1016/0040-1951(87)90011-4.

Passelègue, F. X., Schubnel, A., Nielsen, S., Bhat, H. S., Deldicque, D., \& Madariaga, R. (2016). Dynamic rupture processes inferred from laboratory microearthquakes. Journal of Geophysical Research: Solid Earth, 121(6), 4343-4365.

Power, W. L., Tullis, T. E., Weeks, J. D., 1988. Roughness and wear during brittle faulting. Journal of Geophysical Research: Solid Earth, 93, 15268-15278. doi: 10.1029/JB093iB12p15268.

Rastei, M. V., Heinrich, B., Callani, J. L., 2013. Puckering stick-slip friction induced by a sliding nanoscale contact. Physical Review Letters, 111, 084301. doi:10.1103/PhysRevLett.111.084301.

Reches, Z., Lockner, D. A., 2010. Fault weakening and earthquake instability by powder lubrication. Nature,467, 452-455. doi:10.1038/nature09348.

Rubinstein, S. M., Barel, I., Reches, Z., Braun, O. M., Urbakh, M., Fineberg, J., 2011. Slip sequences in laboratory experiments resulting from inhomogeneous shear as analogs of earthquakes associated with a fault edge. Pure and Applied Geophysics, 168, 2151-2166. doi: 10.1007/s00024-010-0239-1. 
Sagy, A., Brodsky, E. E., Axen, G. J., 2007. Evolution of fault-sirface roughness with slip. Geology, 35, 283-286. doi: 10.1130/G23235A.1.

Savage, J. C., Byerlee, J. D., \& Lockner, D. A., 1996. Is internal friction friction?. Geophysical research letters, 23(5), 487-490.

Scholz, C. H., 1992. Paradigms or small change in earthquake mechanics. International Geophysics, 51, 505-517. doi:10.1016/S0074-6142(08)62836-3.

Scholz, C. H., 1998. Earthquakes and friction laws. Nature, 391, 37-42. doi:10.1038/34097.

Scholz, C. H., Engelder, J. T., 1976. The role of asperity indentation and ploughing in rock friction - I: Asperity creep and stick-slip. International Journal of Rock Mechanics and Mining Sciences \& Geomechanics Abstracts, 13, 149-154. doi:10.1016/0148-9062(76)908196.

Scuderi, M. M., Carpenter, B. M., Marone, C., 2014. Physicochemical processes of frictional healing: Effects of water on stick-slip stress drop and friction of granular fault gouge. Journal of Geophysical Research: Solid Earth, 119, 4090-4105. doi:10.1002/2013JB010641.

Svetlizky, I., Fineberg, J., 2014. Classical shear cracks drive the onset of dry frictional motion. Nature, 509, 205-208. doi:10.1038/nature13202.

Tabor, D., 1975. Interaction between surfaces: Adhesion and friction. in Blakely, J. M. eds. Surface physics of materials, Ch. 10. Academic Press, New York, San Francisco, London.

Tabor, D., 1981. Friction - The present state of our understanding. Journal of Lubrication Technology, 103, 169-179. doi:10.1115/1.3251622.

Tabor, D., 2006. Friction, lubrication, and wear, in Rothbart, H. A., Brown, T. H., eds. Mechanical Design Handbook, Second Edition: Measurement, Analysis and Control of Dynamic Systems, 7.1-7.25.

Tesei, T., Carpenter, B. M., Giorgetti, C., Scuderi, M. M., Sagy, A., Scarlato, P., Collettini, C., 2017. Friction and scale-dependent deformation processes of large experimental carbonate faults. Journal of Structural Geology, 100, 12-23. doi:10.1016/j.jsg.2017.05.008.

Wawersik, W. R., Brace W. F., 1971. Post-failure behavior of a granite and diabase, Rock Mechanics, 3, 61- 85. doi: 10.1007/BF01239627.

Whitehouse, D. J., Archard, J. F., 1970. The properties of random surfaces of significance in their contact. Proceedings of the Royal Society A, 316, 97-121. doi:10.1098/rspa.1970.0068.

Yamashita, F., Fukuyama, E., Xu, S., Mizoguchi, K., Kawakata, H., Takizawa, S., 2018. Rupture preparation process controlled by surface roughness on meter-scale laboratory fault. Tectonophysics, 733, 193-208. doi:10.1016/j.tecto.2018.01.034. 